ojs.uv.es/index.php/qfilologia/index

Rebut: I6.06.2020. Acceptat: 30.07.2020

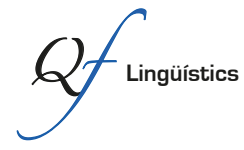

Per a citar aquest article: Martins, Cristina. 2020. "Estudos sobre a aquisição/aprendizagem do género nominal por aprendentes de português língua não materna: valências pedagógicas”. Quaderns de Filologia: Estudis Lingüístics XXV: $169-184$.

doi: $10.7203 /$ QF.25.19078

\title{
Estudos sobre a aquisição/aprendizagem do género nominal por aprendentes de português língua não materna: valências pedagógicas
}

\author{
Studies on the Acquisition / Learning of Nominal Gender by Non-native Learners \\ of Portuguese: Pedagogical Relevance
}

\author{
Cristina MARTins \\ Universidade de Coimbra, CELGA-ILTEC, FLUC \\ crismar@fl.uc.pt
}

Resumo: O género nominal (quer a atribuição do valor, quer a concordância) é uma estrutura reconhecidamente crítica para aprendentes do português como língua não materna (PLNM), havendo já vários estudos relativos à aquisição/aprendizagem do português que o comprovam (Ferreira, 20II e 20I9; Godinho, 20I0; Leiria, 2006; Li \& Flores, 20I9; Mariotto \& Lourenço-Gomes, 20I3; Mariotto, 20I4; Lacsán, 20I5; Martins, 20I5; Pinto, 20I5 e Silva, 20I8). Neste trabalho, estes estudos são analisados tendo em vista o aproveitamento pedagógico dos seus resultados e considerando o seu eventual contributo para a descrição do built-in syllabus (Corder, I967) dos aprendentes de PLNM. Uma análise desta natureza, de que atualmente se carece, torna-se particularmente relevante para orientar o desenho instrutivo.

Palavras chave: género nominal; português língua não materna; português língua estrangeira; desenvolvimento interlinguístico; desenho instrutivo.

Abstract: Nominal gender (both value assignment and agreement) is one of the most challenging stuctures for learners of Portuguese as a non-native language (PNNL), as existing studies on the acquisition of Portuguese have demonstrated (Ferreira, 20II and 20I9; Godinho, 20I0; Leiria, 2006; Li \& Flores, 20I9; Mariotto \& Lourenço-Gomes, 20I3; Mariotto, 20I4; Lacsán, 20I5; Martins, 20I5; Pinto, 2015, and Silva, 2018). In this paper, these studies are examined in the light of the pedagogical implications of their findings, considering their potential contribution to the description of PNNL learners' built-in syllabus (Corder, I967). Such an analysis, although currently lacking, is of utmost importance for guiding instructional design.

Keywords: nominal gender; Portuguese as a non-native language; Portuguese as a foreign language; interlanguage development; instructional design. 


\section{Introdução}

Um dos (poucos) consensos que emana da investigação sobre a aquisição/ aprendizagem de línguas não maternas (LNM) é o de que os aprendentes desenvolvem as respetivas interlínguas guiados pelo que Corder (I967) designou o seu built-in syllabus. Trata-se de um programa interno que determina a sequenciação sistemática de estruturas no desenvolvimento interlinguístico dos aprendentes de uma dada LNM e que parece ser insensível ao efeito de variáveis como a língua materna (LM) dos aprendentes e o contexto (naturalístico ou instrucional) em que o processo de aquisição/aprendizagem ocorre.

Não podendo subverter o built-in syllabus dos aprendentes (Ellis, 2005; Long, 20II), o ensino da LNM pode, no entanto, ter um impacto significativo no ritmo a que este se desenrola e, também, no grau de precisão gramatical atingido pelo aprendentes no end state (Long, I988; Larsen-Freeman \& Long, I99I). Em prol da sua maior eficácia nestes âmbitos, o ensino da LNM ganha, portanto, em levar em devida conta as características do desenvolvimento interlinguístico dos aprendentes. Nesta linha, admita-se que a experiência instrucional será tanto mais benéfica para os aprendentes quanto o desenho instrutivo não ignore os resultados que a investigação sobre aquisição/aprendizagem dessa LNM tem apurado. É, assim, e na perspetiva da Linguística Aplicada ao Ensino, importante coligir a informação disponível sobre aquisição/aprendizagem das estruturas que se têm revelado mais críticas para os aprendentes de uma dada LNM, a fim de avaliar as respetivas valências pedagógicas. No caso do português como língua não materna (PLNM) essa tarefa está, em larga medida, por realizar.

O presente trabalho pretende contribuir para este empreendimento no que especificamente concerne à aquisição/aprendizagem do género nominal, através de uma revisão dos estudos existentes com informação relevante a este respeito, nomeadamente os de Ferreira (20II e 20I9), Godinho (20I0), Leiria (2006), Mariotto \& Lourenço-Gomes (20I3), Mariotto (20I4), Lacsán

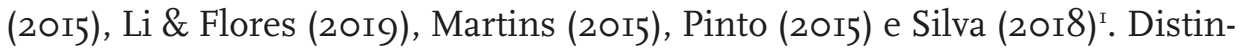
tos nos seus objetivos específicos, nos enquadramentos teóricos adotados, no tipo de dados analisados e nos perfis de aprendentes considerados, estes estu-

\footnotetext{
${ }^{\mathrm{I}}$ Fora do escopo do presente trabalho ficam os estudos sobre a aquisição/aprendizagem do português em contextos, nomeadamente os ex-coloniais, em que este idioma assume o estatuto de língua segunda (LS).
} 
dos fornecem, ainda assim, resultados de natureza descritiva e com interesse pedagógico que importa coligir.

\section{Particularidades do género nominal em português com relevância para aprendentes não nativos}

O género é uma categoria gramatical com dois valores em português (masculino; feminino), cuja atribuição, ao nome, é altamente arbitrária. Por um lado, poucos são os nomes cujo valor de género é semanticamente motivado, i.e., são poucos os nomes [+animados; +sexuados] cujos valores de género coincidem com o sexo dos respetivos referentes extralinguísticos. Por outro lado, e se cerca de $60 \%$ dos nomes integra a classe temática -0 , sendo masculinos, ou a classe temática $-a$, sendo femininos (Ferreira, 20II), a correlação entre índice temático (IT) e valor de género não é universal entre os nomes destas classes (por ex., dia masc, $_{\text {, }}$ tribo fem $_{\text {) }}$ ), o que configura uma situação de correlação apenas parcial entre estes IT e os valores de género referidos. Por fim, os demais cerca de $40 \%$ dos nomes integram outras classes temáticas (nomes em $-e$, em - $\varnothing^{2}$ e atemáticos) (Ferreira, 20II), em que não se observa qualquer correlação entre IT e valor de género nominal. Nestas circunstâncias, a confiabilidade dos IT enquanto indícios morfológicos robustos ao serviço da marcação do valor de género do nome é reduzida. Outro indício morfológico, constituído pelos sufixos derivacionais que geram produtos nominais e que carreiam, cada um, um valor de género específico (folh [agem $]_{\mathrm{fem}}$; batat $\left.[\text { al }]_{\text {masc }}\right)$, serão, ainda assim, e dada a sua heterogeneidade formal, pouco salientes tomados por si só, i.e., sem a coocorrência dos IT $-o$ ou $-a$. Deste modo, enquanto, por exemplo, $-e z$ e $-e z$ (a) são ambos sufixos derivacionais que geram produtos nominais deadjetivais femininos (estudipez, beleza), os produtos derivados em $-e z(a)$ serão, e na ausência de estratégias explícitas de sensibilização dos aprendentes para o valor de género de cada sufixo, mais facilmente reconhecidos como femininos, dada a coocorrência do IT $-a$.

Contrasta com o que se passa dentro das fronteiras do nome a concordância sintática em género que cada um desencadeia. Na verdade, a concordância

\footnotetext{
${ }^{2}$ Os nomes de tema em - $\varnothing$, como $d o r_{\text {fem }}$ e $l i c o r_{\text {masc }}$, assim considerados por Villalva (2000), são classificados, por Mattoso Câmara (I996), como nomes de tema em -e, já que o constituinte temático, ausente na forma do singular, é visível na forma do plural (dores e licores).
} 
nominal em género espoletada pelo nome na estrutura sintática ${ }^{3}$ é, em português, e no caso particular dos constituintes alvo, i.e., especificadores (determinantes e quantificadores) e adjetivos biformes, estável e morfologicamente transparente, criando, para além do mais, redundância nos indícios do valor de género do núcleo nominal ${ }^{4}$.

Se os aprendentes do português como língua materna (PLM) revelam alta sensibilidade aos indícios linguísticos disponíveis para a atribuição dos valores de género nominal, não evidenciando, igualmente, dificuldades no domínio da concordância, o que se traduz numa estabilização precoce desta estrutura ${ }^{5}$, já o mesmo não poderá dizer-se dos aprendentes do PLNM que, mesmo em estádios avançados de proficiência, continuam a acusar desvios neste âmbito. A facilidade de aquisição do género nominal por aprendentes nativos em comparação com a sua maior dificuldade por não nativos configura, de resto, uma tendência comum na aquisição/aprendizagem de várias línguas com esta categoria gramatical (Franceschina, 2005).

Independentemente dos modelos teóricos de aquisição/aprendizagem de LNM que podem ser convocados para explicar este estado de coisas, interessa, neste contexto, identificar as dificuldades dos aprendentes de PLNM descritas nos estudos existentes e, sobretudo, determinar em que medida os resultados disponíveis contribuem para a construção de um modelo de desenvolvimento interlinguístico passível de ser tomado por referência em atividades de desenho instrutivo.

\footnotetext{
3 "Triggers are defined as the lexical items containing intrinsic gender values that can be copied onto other lexical items, namely targets, which are not inherently marked for gender and receive this via syntactic agreement (or concord). (...) Targets are the lexical items that agree with nouns either present in the linguistic context or tacitly implied by it." (Franceschina, 2005: 7I-72). Esta perspetiva está em conformidade com o entendimento de Corbett (I99I) de que o género é um sistema de classificação nominal que implica concordância. Acrescente-se que o género tem vindo a ser entendido ora como uma propriedade lexicossintática (Barber \& Carreiras, 2005), ora como uma categoria morfossintática não realizada por flexão (Villalva, 2000).

4 Ainda que a atribuição dos valores de género ao nome e a concordância dela decorrente representem dois fenómenos distintos, a verdade é que, e em função da fraca robustez dos indícios morfológicos, a avaliação do valor de género atribuído ao nome em português só pode ser cabalmente determinado pela observação da concordância nominal. É a perspetiva que se adota no presente trabalho, ainda que esta não seja partilhada por alguns autores dos estudos aqui revistos.

${ }_{5}$ Cf., por exemplo, sobre a aquisição precoce do português, Choupina et al. (20ı6); Corrêa \& Augusto (20I7); Costa et al. (20I5).
} 


\section{Caracterização dos estudos}

Como se referiu, os estudos existentes diferem quanto ao número e ao perfil dos aprendentes considerados, quer no que diz respeito às suas LM, quer no que concerne aos seus níveis de proficiência (tabela I), sendo de salientar, no entanto, que todos recorrem a amostras de estudantes universitários que, na maior parte dos casos, se encontravam em contexto imersivo à altura da recolha de dados ${ }^{6}$.

\begin{tabular}{|c|c|c|c|}
\hline \multirow[b]{2}{*}{ Estudo } & \multicolumn{3}{|c|}{ Participantes } \\
\hline & $N r$ & $\begin{array}{c}\text { Dados sobre níveis de } \\
\text { proficiência }\end{array}$ & $L M$ \\
\hline Godinho (2010) & 17 & $\begin{array}{l}\text { 56oh, 840h e } 1120 h \text { de } \\
\text { ensino }\end{array}$ & chinês (cantonês) \\
\hline Ferreira (2011) & 256 & $\mathrm{~A}_{1}, \mathrm{~A}_{2}, \mathrm{~B}_{1}, \mathrm{~B}_{2}, \mathrm{C}_{1}$ & 37 LM diferentes \\
\hline Ferreira (2019) & 506 & $\mathrm{~A}_{1} / \mathrm{A}_{2}, \mathrm{~B}_{1} / \mathrm{B}_{2}, \mathrm{C}_{1}$ & $\begin{array}{c}\text { espanhol, italiano, alemão, inglês, } \\
\text { chinês }\end{array}$ \\
\hline Lacsán (2015) & 36 & $\mathrm{~A}_{2} / \mathrm{B}_{1}, \mathrm{~B}_{2}, \mathrm{C}_{1}$ & húngaro \\
\hline Leiria (2006) & 257 & $\begin{array}{l}\text { Curso básico de PLE (1 } \\
\text { ou } 2 \text { semestres) }\end{array}$ & $\begin{array}{c}\text { espanhol, francês, alemão, sueco, } \\
\text { chinês }\end{array}$ \\
\hline Li \& Flores (2019) & 15 & avançado & chinês (mandarim) \\
\hline $\begin{array}{l}\text { Mariotto \& Lou- } \\
\text { renço-Gomes } \\
(2013)\end{array}$ & 56 & $\mathrm{~A}_{1} / \mathrm{A}_{2}, \mathrm{~B}_{1} / \mathrm{B}_{2}$ & inglês, espanhol \\
\hline Mariotto (2014) & 48 & $\mathrm{~B}_{1}$ & inglês \\
\hline Martins (2015) & 90 & $\mathrm{~A}_{2}, \mathrm{~B}_{1}, \mathrm{~B}_{2} / \mathrm{C}_{1}$ & espanhol, alemão, chinês \\
\hline Pinto (2015) & 31 & $\begin{array}{c}1^{\circ}, 2^{\circ} \text { e } 3^{\circ} \text { anos de li- } \\
\text { cenciatura }\end{array}$ & árabe marroquino \\
\hline Silva (2018) & 27 & $A_{1}, A_{2}$ & 17 LM diferentes \\
\hline
\end{tabular}

Tabela I - Perfis das amostras de sujeitos

À exceção dos sujeitos estudados por Mariotto (20I4), expostos ao português do Brasil, todos os demais adquiriam o português europeu?

\footnotetext{
${ }^{6}$ Os participantes nos estudos de Godinho (20I0) e Pinto (20I5) e uma subamostra de o de Lacsán (20I5) encontravam-se em contexto não imersivo.

7 Não se excluiu o estudo de Mariotto (20I4) da presente revisão, uma vez que a atribuição dos valores de género nominal e concordância não difere no português do Brasil ( $\mathrm{PB}$ ) e no
} 
Em função dos perfis das amostras de aprendentes, algumas das análises disponíveis permitem tecer considerações sobre o desenvolvimento das interlínguas em fases distintas do processo em associação com o papel da LM dos aprendentes nos comportamentos observados (Ferreira, 20I9; Mariotto \& Lourenço-Gomes, 20I3; Martins, 20I5). Em todo o caso, nem todos os estudos que avaliam aprendentes com LM diferentes procedem ao confronto dos dados atendendo a esta variável ${ }^{8}$, enquanto outros, que estudam grupos homogéneos de aprendentes quanto à LM e/ou ao conhecimento de outras LNM, consideram, mesmo assim, efeitos de transferência nos comportamentos observados (Pinto, 2015; Lacsán, 20159).

Também a natureza dos dados trabalhados é distinta em cada estudo. Se na maioria se analisam dados de corpora de produções escritas, Godinho (20I0) e Silva (20I8) observaram produções orais, ora semi-espontâneas, ora resultantes da descrição de imagens. Nos demais estudos foram elicitados dados de vários tipos, através de (i) um teste cloze com escolha múltipla de artigos definidos e de adjetivos biformes (Lacsán, 20I5), (ii) uma tarefa de repetição oral de frases gramaticais e agramaticais (Li \& Flores, 20I9) e (iii) uma tarefa de leitura de frases gramaticais e agramaticais em que se manipulou a concordância nome-adjetivo com função predicativa (Mariotto, 20I4). Os estudos de Li \& Flores (20I9) e de Mariotto (20I4) incluem, ainda, resultados de testes de juízos de gramaticalidade.

Os objetivos mais específicos de cada estudo revelam, igualmente, alguma diversidade. Se uns se centram fundamentalmente na análise dos padrões de atribuição de valores de género e respetiva concordância pelos aprendentes (Ferreira, 20II e 20I9; Lacsán, 20I5; Mariotto, 20I4; Mariotto \& Lourenço-Gomes, 20I3; Pinto, 20I5), outros contrastam estes padrões com os da aquisição da concordância nominal em número (Godinho, 20Io; Martins, 20I5; Silva, 20I8), havendo, ainda, o de Li \& Flores (2019), que considera aspetos morfossintáticos relativos a nomes e verbos, para além do uso de tempos verbais, e o de Leiria (2006), que incide sobre a aquisição do léxico.

português europeu, ao contrário do que acontece com a concordância nominal em número. No PB, apenas "se registra um nível significativo de variação na concordância de gênero em certas comunidades rurais que passaram por um amplo e profundo contato linguístico em sua história" (Lucchesi, 2009: 305).

${ }^{8}$ Não o fazem, por exemplo, Ferreira (20II) e Silva (20I8).

9 Lacsán (20I5) procura, com este exercício, testar a Failed Functional Features Hypothesis (Hawkins \& Chan, I997). 
Salvaguardadas as suas especificidades, estes estudos distintos apresentem, ainda assim, alguns resultados convergentes. Destacar-se-ão, na secção seguinte, os que assumem particular interesse numa perspetiva pedagógica.

\section{Resultados com relevância pedagógica}

A primeira observação pedagogicamente pertinente prende-se com o facto de ficar claro, em vários estudos, que, no que toca à atribuição do valor de género nominal e respetiva concordância, os aprendentes tendem a acertar muito mais do que erram ${ }^{\text {ro }}$, sendo esta uma tendência que se repete independentemente da natureza dos dados analisados. Assim, Lacsán (2015) apurou elevados índices de acerto em todos os segmentos da amostra estudada, nos dados elicitados através de uma tarefa cloze com escolha múltipla de artigos e adjetivos $^{\text {II }}$, e o mesmo apuraram Ferreira (20II e 20I9), Leiria (2006), Mariotto \& Lourenço-Gomes (20I3), Martins (20I5) e Pinto (20I5), em dados extraídos de corpora de produções escritas, bem como Godinho (20I0), já em dados de produção oral. Deste modo, e ainda que se trate de uma área crítica para os aprendentes de PLNM, a primeira conclusão importante a retirar é a de que as dificuldades, neste âmbito, se manifestam de um modo razoavelmente circunscrito.

Com vista à identificação dos fatores que potenciam desvios deste tipo, considere-se, em primeiro lugar, o que apurou Leiria (2006), nomeadamente o facto de os desvios se concentrarem num conjunto restrito de nomes. A autora refere mesmo que, no corpus de produções escritas que estudou, 24 $\%$ das ocorrências desviantes dizem respeito a apenas cinco nomes muito frequentes (num universo de 3026): cidade, problema, viagem, pessoa e gente. Ainda a este propósito, e sendo certo que os dados de Leiria (2006) foram produzidos por aprendentes pouco diversificados quanto aos seus níveis de proficiência, a informação da autora pode ser utilmente complementada com a que fornece Ferreira (20II e 20I9), que, tendo analisado dados de aprendentes diversificados quanto a esta variável, inventaria os nomes das diferentes

\footnotetext{
ro Trata-se de um padrão recorrente, e independentemente da estrutura linguística em causa, observado nos estudos que têm confrontado, sistematicamente, ocorrências divergentes e convergentes com a língua-alvo (LA). A enumeração de alguns estudos sobre PLNM que adotam esta metodologia encontra-se em Lopes \& Martins (20I7: I72, n.7).

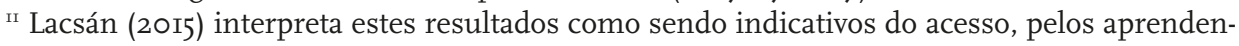
tes, à Gramática Universal.
} 
categorias de análise que considerou (combinando critérios formais e semânticos) e que, em cada nível de proficiência, se revelaram mais problemáticos ${ }^{12}$, dando, também assim, uma útil indicação sobre alguns dos que devem merecer particular atenção em contexto instrucional ${ }^{13}$. Entre estes, destacam-se os que recorrem em diferentes níveis de proficiência. No estudo de Ferreira (20II), por exemplo, e dos 256 nomes que acusam desvios, são 70 os que registam ocorrências em mais do que um nível de proficiência. Destes últimos, II ainda surgem, com desvios, nas produções escritas de aprendentes do nível Cr: atividade, campo, capital, cidade, cinema, colega, discoteca, lugar, oportunidade, parte, problema, universidade, vez.

Outra observação relevante remete para a relação entre desvios e classes temáticas dos nomes, variável explicitamente considerada em alguns estudos ou cujo efeito se pode inferir, noutros, a partir dos dados fornecidos. Se prevalecem, entre os nomes mais problemáticos, e como se esperaria, os [-animados] $]^{14}$ de tema em -e, em - $\varnothing$ e os atemáticos (Ferreira, 20II e 20I9; Leiria, 2006; Martins, 2015; Pinto, 20155), registando-se um melhor desempenho global no caso dos nomes de tema em -o e - $a$ (Lacsán, 20I5; Leiria, 2006), a verdade é que estes últimos também se revelam surpreendentemente problemáticos em alguns dos estudos. Neste sentido, deve assinalar-se a expressão relevante de desvios não apenas entre os nomes masculinos de tema em $-a$ (Ferreira, 2019; Leiria, 2006; Pinto, 2015) ${ }^{16}$, o que, mais uma vez, se esperaria, mas também entre os que exibem, em português, a correlação mais co-

\footnotetext{
${ }^{12}$ Cf. os quadros 3.9 a I3.I2 apresentados em Ferreira (20II) e os quadros 4.9, 4.II, 4.I4 e 4.23 em Ferreira (2019).

${ }^{13}$ Martins (2015) também identifica os nomes afetados por desvios, organizados por classes temáticas (cf. tabela io neste estudo).

${ }^{14}$ Mariotto (2OI4), no entanto, não apurou uma diferença nos resultados relativos aos nomes [ \pm animados]. Este resultado pode dever-se ao desenho metodológico do estudo em questão, pois só foram contabilizados casos de concordância nome-adjetivo com função predicativa, contrariamente ao que acontece noutros trabalhos em que, para além destas estruturas, também foram considerados casos de concordância especificador-nome, de concordância nome-adjetivo com função atributiva e de alterações formais na morfologia do nome (i. e., nos IT). Assim, é possível postular que a oposição [ \pm animado] não assumirá relevância de maior no domínio da concordância nome-adjetivo com função predicativa, sem se excluir a sua pertinência nos padrões de atribuição dos valores de género ao nome manifestados por outros meios.

Is Entre os atemáticos, Pinto (2015) destaca, num grupo à parte, e com índices assinaláveis de desvios, os terminados em - ̃̃o (sufixal e não sufixal), realçando, muito em particular, a tendência para que estes sejam considerados masculinos, quando, na LA, são femininos. Estes nomes também se revelaram problemáticos no estudo de Ferreira (2019).

${ }^{16}$ São muito esporádicos os desvios que atingem os nomes femininos de tema em -o (Ferreira, 2019; Martins, 2015).
} 
mum entre masculino/IT-o e feminino/IT- $a$ (Ferreira, 20II e 20I9; Martins, 20I5; Pinto, 20I5). Nestes últimos casos (e também nos de nomes femininos de outras classes), predominam as situações em que nomes femininos são erroneamente tomados como sendo masculinos, o que revela o recurso, pelos aprendentes, a uma estratégia de masculino por defeito (Ferreira, 20I9; Li \& Flores, 20I9; Mariotto \& Lourenço-Gomes, 20I3; Martins, 20I5; Pinto, 20I5). Daqui decorre que os nomes femininos (de qualquer classe), são mais vulneráveis a desvios de atribuição do valor de género e respetiva concordância (Ferreira, 2019).

A ocorrência de desvios entre os nomes que representam o paradigma masculino/IT-o e feminino/IT- $a$, de que também não estão isentas as produções de aprendentes dos níveis mais avançados, é muito interessante porque indicia a desconfiança dos aprendentes em relação à confiabilidade de estes dois IT como marcadores do valor de género dos nomes (Ferreira, 20II e 2019) e revela, também assim, a sua acuidade em relação à fraca robustez dos indícios morfológicos para este fim. Contudo, e por outro lado, o melhor desempenho relativo no caso dos nomes em que a correlação mais comum entre IT e género subsiste é igualmente indicativa da sensibilidade dos aprendentes a um padrão que, não sendo particularmente robusto, ainda assim existe na LA $^{17}$. Admitimos que estes dados sugerem a mobilização, pelos aprendentes, de uma estratégia inferencial geral que, a partir dos indícios existentes no input linguístico, lhes permite a extração não apenas de padrões de correlação IT/género, mas também a perceção dos limites destes padrões.

Mas pode argumentar-se que os resultados evocados também sugerem a mobilização de uma outra estratégia, alternativa e complementar à de inferência geral de relações forma-função. A elevada taxa global de acertos e a ocorrência de fenómenos desviantes em relação a itens lexicais específicos, a par de uma certa desconsideração pelo papel do IT na marcação do género do nome, são observações que, tomadas em conjunto, são igualmente compatíveis com a sugestão de que, entre as estratégias possíveis de aquisição/ aprendizagem do valor de género, o aprendente adota uma que consiste na fixação desse valor, e em última análise, item a item (Ferreira, 20ıı; Pinto, 20I5).

\footnotetext{
17 Segundo Ferreira (2019) essa sensibilidade é mais apurada entre os aprendentes cuja LM é tipologicamente mais próxima da LA, tendência que é mais saliente nos níveis iniciais de aquisição/aprendizagem, como adiante se verá.
} 
Confluem para a plausibilidade desta hipótese duas circunstâncias. Em primeiro lugar, os estudos que assinalam índices elevados de acerto na identificação do valor de género dos nomes baseiam-se em itens lexicais que figurarão, com toda a probabilidade, entre os mais conhecidos dos aprendentes. Com efeito, Lacsán (20I5) e Godinho (20I0) selecionaram, para os respetivos testes de elicitação de dados, nomes extraídos de manuais de ensino de ampla divulgação, ajustados aos níveis dos aprendentes das amostras, e os demais estudos consideram nomes extraídos de produções escritas e orais que correspondem, presumivelmente, àqueles com os quais os aprendentes se sentem mais confortáveis. Tratando-se de um nome conhecido, aumenta a probabilidade de o aprendente dominar várias das suas propriedades, incluindo o seu valor de género. Em segundo lugar, contribui para fundamentar a assunção de que o valor de género nominal é, em última instância, fixado com recurso a uma estratégia "item a item" a observação de Ferreira (20II), segundo a qual os padrões de desvios observados em cada nível de proficiência, atendendo às categorias de nomes que criou cruzando os critérios da animacidade e do IT, se repetem, com proporções similares, em todos os níveis de proficiência. Quer isto dizer que os aprendentes, produzindo menos desvios com o avanço da proficiência, não exibem, no entanto, padrões distintos de desvios, atendendo à categoria do nome, em cada nível. Assim sendo, as dificuldades dos aprendentes dos níveis iniciais e dos níveis avançados recaem, com proporções semelhantes, nos mesmos tipos de nomes, mas não predominantemente, como se viu, nos mesmos nomes.

Regista-se, portanto, e como seria de esperar, uma melhoria do desempenho dos aprendentes com o avanço do seu nível de proficiência, tal como a contabilização do número de desvios empreendida em vários estudos demonstra (Godinho, 20Io; Ferreira 20II e 20I9; Lacsán, 20I5; Martins, 20I5; Pinto 20I5). Relevantemente, em alguns destes estudos observou-se, a partir dos níveis intermédios, um efeito plateau, i.e., a estagnação na tendência de melhoria do desempenho dos aprendentes. Assim, a uma descida mais abrupta do número de desvios dos níveis iniciais para os intermédios, ocorre, aí, uma estabilização desse número até ao nível Ci (Ferreira, 20II e 20I9 ${ }^{\text {I8; }}$ Lacsán, 20I5; Martins, 20I5). Este padrão indicia os efeitos positivos do tempo

\footnotetext{
${ }^{18}$ No entanto, segundo apurou Ferreira (20I9), a melhoria dos aprendentes cuja LM é o chinês só se regista de modo notório na passagem dos níveis Bi/B2 para o nível Ci. Por outro lado, os aprendentes de LM espanhola estabilizam mais cedo do que os demais os baixos níveis de ocorrências desviantes.
} 
de exposição ao input da língua-alvo (LA) ou mesmo do processo instrucional neste domínio (Lacsán, 20I5), que não terá, no entanto, um impacto tão relevante na passagem dos níveis intermédios para os mais avançados. Parece ser, portanto, a partir dos níveis $\mathrm{BI} / \mathrm{B} 2$ que se registam os maiores riscos de fossilização do conhecimento interlinguístico não convergente com a LA neste domínio.

Sendo nos níveis iniciais que as maiores dificuldades se registam, estas serão tanto maiores quanto a LM ou as outras LNM conhecidas dos aprendentes se afastam, tipologicamente, do português no que a esta propriedade gramatical diz respeito (Ferreira, 20I9; Lacsán, 20I5; Leiria, 2006; Mariotto \& Lourenço-Gomes, 2013). Contudo, a partir dos níveis intermédios, não só o efeito LM/conhecimento linguístico prévio de outras LNM se esbate, como os desvios, na generalidade dos aprendentes, diminuem de modo relevante, como se viu. No estudo de Lacsán (20I5), são mesmo os aprendentes húngaros sem conhecimento prévio de línguas românicas os que, a partir dos níveis de proficiência intermédios, melhor desempenho evidenciam. Vantagem semelhante de aprendentes com LM chinesa e alemã face aos de LM espanhola foi detetada por Martins (20I5), o que sugere que a existência, na LM ou nas outras LNM conhecidas, de um sistema de género similar ao do português pode ser mais perturbador para a estabilização desta estrutura de um modo convergente com a LA do que a sua inexistência.

Como se observa, dos estudos disponíveis emana uma imagem pouco clara da forma como atua o conhecimento da LM e de outras LNM nos comportamentos dos aprendentes. A influência desta variável parece traduzir-se mais no ritmo a que os aprendentes com conhecimento prévio de línguas tipologicamente próximas do português progridem pelas fases de construção das respetivas interlínguas do que na transferência direta de valores de género a partir de nomes semanticamente equivalentes dessas línguas. Assim, e tal como apurou Ferreira (2019) nos dados de aprendentes de LM espanhola e italiana, a transferência direta do valor de género de nomes do espanhol e do italiano explicará uma minoria dos desvios que atingem os nomes portugueses do tipo IT-o/masculino e IT-a/feminino, mas poderá, em teoria, ser responsável por cerca de $60 \%$ dos casos de desvios em nomes de tema em -e, em - $\varnothing$ e atemáticos.

Por fim, e no que à concordância em género diz mais restritamente respeito, existe também, entre os estudos revistos, alguma dispersão na identificação do constituinte mais afetado pelo comportamento desviante. Assim, se a maior parte dos estudos identifica os especificadores (e, em particular, os 
determinantes) como os constituintes mais afetados por desvios de concordância (Ferreira, 20II e 20I9; Mariotto \& Lourenço-Gomes, 20I3; Martins, 20I5; Pinto, 20I5; Silva, 20I8), outros assinalam o adjetivo como o constituinte mais afetado (Godinho, 20I0; Lacsán, 20I5) 19. Registe-se, ainda, neste domínio, a existência de enunciados com concordância "mista" (Ferreira, 20I9; Lacsán, 20I5; Pinto, 20I5), caracterizados pela seleção adequada da forma de um dos constituintes concordantes com o nome e a inadequada seleção de outro desses constituintes.

\section{Considerações finais}

Da revisão de estudos empreendida, sobressaem vários resultados com interesse pedagógico, a levar em conta em contexto instrucional. Em primeiro lugar, ficou claro que os aprendentes atribuem mais frequentemente o adequado valor de género ao nome do que registam ocorrências não convergentes com a LA, tendo-se, assim, evidenciado que a atribuição de valores erróneos de género nominal e concordância desviante são, ainda assim, fenómenos razoavelmente circuscritos. Na verdade, os problemas registam-se, sobretudo, em certas categorias de nomes, por um lado, e em certos nomes, por outro.

Entre os nomes mais problemáticos figuram os [-animados] de tema em-e, em - $\varnothing$ e os atemáticos, sem que, no entanto, os de tema em - $a$ e em -o escapem a numerosos desvios deste tipo. Este padrão sugere, como se argumentou, a operacionalização, pelos aprendentes, de uma estratégia de natureza inferencial, que passa pela consideração dos indícios morfológicos disponíveis para atribuir o valor adequado de género ao nome, por um lado, e para sinalizar os seus limites, por outro. A ser assim, são resultados que sugerem a pertinência de, em contexto instrucional, não apenas se sublinhar a correlação entre os IT $-o$ e $-a$ e os valores de género prototípicos dos nomes que pertencem a estas classes temáticas (o que é hábito fazer-se), mas também, e especialmente no que concerne aos nomes que integram outras classes,

\footnotetext{
19 Porventura, diferenças de desenho metodológico dos estudos explicarão algumas destas discrepâncias. No estudo de Lacsán (2015), por exemplo, os participantes tinham de selecionar, em cada frase de teste, determinantes e adjetivos, enquanto os estudos baseados em corpora registam as ocorrências efetivas dos aprendentes em produções não condicionadas do ponto de vista da sua estrutura. Ainda assim, Godinho (20I0), baseando-se em dados de um corpus oral produzidos por aprendentes chineses falantes de cantonês, apurou índices mais elevados de adequada concordância determinante-nome do que de concordância nome-adjetivo.
} 
se orientar a atenção dos aprendentes para as robustas pistas sintáticas que, por via da concordância, estão disponíveis para o efeito. As intervenções pedagógicas devem, portanto, estar especialmente centradas no reconhecimento e na consolidação de padrões de concordância sintática plena, quer entre especificadores e nomes, quer entre nomes e adjetivos biformes. Como se viu, os nomes femininos são especialmente vulneráveis a desvios deste tipo, pelo que podem constituir um bom ponto de partida para intervenções assim orientadas.

Os resultados apurados também aconselham a necessidade de uma atenção particular a itens lexicais específicos que se têm revelado especialmente problemáticos, entre os quais os recenseados por Ferreira (20II e 20I9), Leiria (2006) e Martins (20I5), com ênfase para aqueles que recorrem nos dados de aprendentes de vários níveis de proficiência. Dito isto, não deixa de ser importante reconhecer que a investigação disponível não fornece informações que permitam discernir o grau de sistematicidade com que cada aprendente, tomado por si só, atribui valores erróneos de género a nomes específicos, uma limitação que impede a correta avaliação do tipo de dificuldade que está em causa em cada caso. A variabilidade individual registada na produção de cada um destes nomes mais problemáticos, questão apenas pontualmente aflorada por Li \& Flores (2019), carece de investigação aprofundada, dadas as implicações pedagógicas que tem. Na verdade, a flutuação na atribuição do valor de género a um dado nome por um único aprendente pode ser reflexo não do seu conhecimento interlinguístico deficitário, mas antes de problemas ao nível do processamento linguístico. A ser este último o caso, impor-se-ão atividades que visem a automatização e a maior fluidez do processamento e não necessariamente as que incidirão sobre a fixação do valor de género gramatical dos nomes afetados. De qualquer modo, será defensável a promoção de estratégias de memorização do valor de género nominal item a item nos casos de nomes que recorrem, com desvios, nas atividades linguísticas de aprendentes de diferentes níveis de proficiência.

O eventual recurso, pelos aprendentes, ao conhecimento prévio de línguas tipologicamente afins ao português para atribuir o valor de género aos nomes da LA parece produzir efeitos mais visíveis nos níveis iniciais de aprendizagem, não sendo, no entanto, inteiramente claro de que modo esse conhecimento atua. Este dado sugere os limites de estratégias pedagógicas que dependam excessivamente de análises contrastivas para este efeito, tanto mais que as vantagens do conhecimento linguístico prévio se desvanecem a partir dos níveis intermédios de proficiência. É, com efeito, a partir deste patamar 
de proficiência que se assiste a alguma estabilização da tendência de melhoria geral e mais acentuada desde os níveis iniciais, o que sugere a necessidade de uma atuação pedagógica orientada no sentido de contrariar a reconhecida propensão de fossilização de valores erróneos de género nominal, tal como ela se tem revelado em aprendentes de níveis mais avançados.

Porventura não se esperará (nem se deve esperar) do aprendente de uma LNM uma convergência plena com a gramática da LA. Dito isto, também é certo que, entre os estudos revistos, alguns, baseados em corpora (Ferreira, 20I9; Martins, 20I5), dão conta da existência de textos escritos, até por aprendentes de nível $\mathrm{A} 2$, em que não ocorrem desvios de género nominal. Este dado não garante a ausência de desvios de género nas demais produções destes mesmos aprendentes, mas sugere a possibilidade de que existam, de facto, alguns para quem este problema não se coloque de modo evidente ou mesmo de todo. Tal como se refere em Martins (20I5), falta investigação que dilucide as estratégias cognitivas adotadas por aprendentes com estas características, tendo em vista a promoção de atividades de ensino que as fomentassem e que contribuissem para as disseminar entre os demais aprendentes.

\section{Bibliografia}

Barber, Horacio \& Carreiras, Manuel. 2005. Grammatical Gender and Number Agreement in Spanish: An ERP Comparison. Journal of Cognitive Neuroscience I7(I): I37-I53. doi: I0.II62/0898929052880I0I

Choupina, Celda; Baptista, Adriana; Costa, José António; Oliveira, Inês \& Querido, Joana (20I6). Conhecimentos e regras explícitos e implícitos sobre o género linguístico nos alunos dos $\mathrm{I}^{\circ}$ e $2^{\circ}$ ciclos do Ensino Básico. Revista da Associação Portuguesa de Linguística I(I): 20I-23r. http://ojs.letras.up.pt/index.php/APL/ article/view/I590/I4I3 [Acesso 22/I/2020].

Corbett, Greville. I99I. Gender. Cambridge: Cambridge University Press.

Corder, Pit. I967. The Significance of Learners' Errors. International Review of Applied Linguistics in Language Teaching 5: I6I-I70.

Corrêa, Letícia Sicuro \& Augusto, Marina (20I7). Primeiros passos na aquisição da sintaxe: o sintagma nominal. Em Freitas, Maria João \& Santos, Ana Lúcia (ed.) Aquisição de língua materna e não materna: questões gerais e dados do português. Berlin: Language Science Press, I2I-I54.

Costa, José António; Choupina, Celda; Baptista, Adriana; Oliveira, Inês \& Querido, Joana. 20I5. Género gramatical: a complexidade do conteúdo e a sua abordagem nos documentos reguladores do ensino do português no ${ }^{0}$ ciclo EB. Exedra I: 322-352. https://dialnet.unirioja.es/servlet/articulo?codigo=6496637 [Acesso IO/I/2020]. 
Ellis, Rod. 2005. Principles of Instructed Language Learning. System 33: 209-224.

Ferreira, Tânia. 20I9. Aquisição/aprendizagem do sistema de atribuição de género nominal em PLNM (Tese de Doutoramento). Coimbra: Universidade de Coimbra. [Estudo Geral. Repositório Científico da UC]. https://estudogeral.sib.uc.pt/ handle/ı03i6/87643?locale $=$ pt

Ferreira, Tânia. 20II. Padrões na aquisição/aprendizagem da marcação do género nominal em português como L2 (Dissertação de Mestrado). Coimbra: Universidade de Coimbra. [Estudo Geral. Repositório Científico da UC]. https://estudogeral. uc.pt/handle/ı0316/18583

Franceschina, Florencia. 2005. Fossilized Second Language Grammars - the Acquisition of Grammatical Gender. Amsterdam/Philadelphia: John Benjamins.

Godinho, Ana Paula. 20ıo. A aquisição da concordância de número e a sua relação com a aquisição da concordância de género: um estudo realizado com aprendentes chineses de português L2. Em Marçalo, Maria João; Lima-Hernandes, $M^{a}$ Célia; Esteves, Elisa; Fonseca, $M^{a}$ do Céu; Gonçalves, Olga; Vilela, Ana Luísa \& Silva, Ana Alexandra (coord.) Lingua portuguesa: ultrapassar fronteiras, juntar culturas. Évora: Universidade de Évora, 28-55. www.simelp2009.uevora. pt/pdf/slg24/02.pdf [Acesso 22/I/2020].

Hawkins, Roger \& Chan, Cecilia. I997. The Partial Availability of Universal Grammar in Second Language Acquisition: the "Failed Functional Features Hypothesis". Second Language Research I3(3): I87-226. doi: 10.1191/026765897671476153

Lacsán, Veronika. 20I5. The Acquisition of Gender Agreement in L2 Portuguese by Adult Hungarian Speakers (Dissertação de Mestrado). Lisboa: Universidade de Lisboa. [Repositório da Universidade de Lisboa]. https://repositorio.ul.pt/handle/I045I/2450 I

Larsen-Freeman, Diane \& Long, Michael. I99I. An Introduction to Second Language Acquisition Research. Harlow: Addison Wesley Longman Limited.

Leiria, Isabel. 2006. Léxico, aquisição e ensino do Português europeu língua não materna. Lisboa: FCG/FCT.

Li, Q Qunying \& Flores, Cristina. 20I9. Conhecimento implícito e explícito da flexão nominal e verbal em português língua não materna um estudo sobre aprendentes chineses. Diacrítica 33(2): 252-277. doi: doi.org/I0.218I4/diacritica.42

Long, Michael. I988. Instructed Interlanguage Development. Em Beebe, L. (ed.) Issues in Second Language Acquisition: Multiple Perspectives. Rowley, MA: Newbury House, II5-I42.

Long, Michael. 20II. Methodological Principles for Language Teaching. Em Long, Michael \& Doughty, Catherine (eds.) The Handbook of Language Teaching. Malden: Blackwell, 373-394.

Lopes, Ana Cristina M. \& Martins, Cristina. 20I7. Para o ensino dos usos dos artigos em PLE: por onde começar? Portuguese Language Journal II: I65-I89.

Lucchesi, Dante. 2009. A concordância de gênero. Em Lucchesi, Dante; Baxter, Alan \& Ribeiro, Ilza (coord.) O português afro-brasileiro. Salvador: EDUFBA, 295-3I8. https://repositorio.ufba.br/ri/bitstream/ufba/209/4/O\%20Portugues\%20 Afro-Brasileiro.pdf [Acesso 22/I/2020]. 
Mariotto, Elisabeta \& Lourenço-Gomes, Maria do Carmo. 20I3. Análise de erros na escrita relacionados à aprendizagem da concordância de gênero por falantes nativos do inglês, aprendentes de português europeu como língua estrangeira. Em Anais do IV Simpósio mundial de estudos de língua portuguesa (SIMELP). Língua portuguesa: ultrapassando fronteiras, unindo culturas. Goiás: Universidade Federal de Góias - Faculdade de Letras, I278-ı285. http://simelp.fflch. usp.br/sites/simelp.fflch.usp.br/files/inline-files/simposio_26.pdf [Acesso 7/I/2020].

Mariotto, Elisabeta. 20I4. Processamento da concordância de género por aprendentes de português como língua estrangeira. Evidências de um estudo de leitura automonitorada (Dissertação de Mestrado). Lisboa: Universidade de Lisboa. [Repositório da Universidade de Lisboa]. https://repositorio.ul.pt/handle/I045I/I5695

Martins, Cristina. 20I5. Número e género nominais no desenvolvimento das interlínguas de aprendentes do português europeu como língua estrangeira. Revista Científica da Universidade Eduardo Mondlane, Série: Letras e Ciências Sociais I(I): 2449. http://www.revistacientifica.uem.mz/index.php/LCS/article/ view/16 [Acesso 7/I/2020].

Mattoso Câmara Jr., Joaquim. I995. Estrutura da língua portuguesa (25 ed.). Petrópolis: Editora Vozes.

Pinto, Jorge. 20I5. A aquisição do género e da concordância de género em português língua terceira ou língua adicional. Em Osório, Paulo \& Grosso, Maria José (eds.) Teorias e usos linguísticos - Aplicações ao português língua não materna. Lisboa: Lidel, 9ı-IIo.

Silva, Ana Alexandra. 2oı8. Construção da concordância nominal em produções orais de aprendentes de PL2 (Dissertação de Mestrado inédita). Coimbra: Universidade de Coimbra.

Villalva, Alina. 2000. Estruturas morfológicas. Unidades e hierarquias nas palavras do português. Lisboa: FCG/FCT. 